\title{
ERICO VERÍSSIMO E JEAN PIAGET: DA LITERATURA INFANTIL À CONSTRUÇÃO DO ESPAÇO PELA CRIANÇA
}

\author{
ERICO VERISSSIMO AND JEAN PIAGET: FROM CHILDREN'S LITERATURE \\ TO THE CONSTRUCTION OF SPACE BY THE CHILD
}

\author{
ERICO VERISSIMO Y JEAN PIAGET: DE LA LITERATURA INFANTIL \\ A LA CONSTRUCCIÓN DEL ESPACIO POR NIÑOS
}

\author{
RAQUEL FENSTERSEIFER WEISSHEIMER ${ }^{1}$ \\ RAFAEL MONTOITO ${ }^{2}$
}

\section{RESUMO}

Partindo da ideia de que a literatura infantil, a partir da contação de histórias, pode ser vista pelos professores como uma aliada para 0 ensino da geometria, esse artigo tem como objetivo principal discutir 0 desenvolvimento das relações topológicas, segundo Piaget, na construção do espaço pela criança, tomando como elemento potencializador para este processo o livro infantil As Aventuras do Avião Vermelho, de Erico Veríssimo. A partir das ações das personagens e do desenrolar da história, foram elaboradas sequências didáticas que visam ao desenvolvimento da construção das relações topológicas. Este artigo, parte de uma pesquisa qualitativa e bibliográfica, apresenta três das sequências didáticas criadas. A pesquisa, como um todo, utiliza-se de referenciais que discutem as teorias de Piaget, a potencialidade da literatura para o ensino de diferentes disciplinas e a impregnação mútua que se dá entre a língua materna e a linguagem matemática, os quais são apresentados brevemente neste texto. Como resultado, percebe-se que é possível, considerando estes referenciais, criar sequências didáticas que instiguem ao desenvolvimento das dimensões topológicas nos anos iniciais, bem como se pensar numa maneira diferente de compor 0 ensino e a aprendizagem de matemática, visando melhorar a capacidade interpretativa do aluno e dando espaço para aspectos subjetivos como a afetividade e a criatividade.

Palavras-chave: Literatura infantil. Relações topológicas. Contação de histórias. Linguagem matemática e língua materna.

\section{ABSTRACT}

Starting from the idea that children's literature, from storytelling, can be seen by teachers as an ally for the teaching of geometry, this paper has as main aim to discuss the development of topological relationships, according to Piaget, in the construction of the space by the kid, taking the children's book As Aventuras do Avião Vermelho, by Erico Veríssimo, as potentializing element to this process. From the actions of the characters and the unfolding of the story, didactic sequences were developed that aim at the development of the construction of topological relations. This paper, part of a qualitative and bibliographic research, presents three of the didactic sequences created. The research, as a whole, uses referentials that discuss Piaget's theories, the potential of literature for teaching different disciplines and the mutual impregnation that occurs between the mother tongue and the mathematical language, which are presented briefly in this text. As a result, it is perceived that it is possible, considering these referentials, to create didactic sequences that instigate the development of topological dimensions in the early years of school, as well as thinking in

1 Mestre em Educação (IFSUL). Professora na Escola Municipal Comunitária Parque Fragata (Capão do Leão/RS); E-mail: raquel.fweissheimer@ gmail.com; ORCID: https://orcid.org/0000-0002-8037-8833

2 Doutor em Educação para a Ciência (UNESP). Professor no Instituto Federal de Educação, Ciência e Tecnologia Sul-rio-grandense (IFSUL) e no Mestrado em Educação Matemática (UFPel); E-mail: xmon-toito@gmail.com; ORCID: https://orcid.org/0000-0002-3294-3711 
a different way of composing the teaching and learning of mathematics, aiming to improve the student's interpretive capacity and giving space to subjective aspects such as affectivity and creativity.

Keywords: Children's literature. Topological relationships. Storytelling. Mathematical language and mother tongue.

\section{RESUMEN}

Partiendo de la idea de que la literatura infantil basada en la narración puede ser vista por los maestros como un aliado para la enseñanza de la geometria, este artículo tiene como principal objetivo discutir el desarrollo de las relaciones topológicas, según Piaget, en la construcción del espacio por parte del niño, tomando como elemento potencializador de este proceso el libro infantil As aventuras do avião vermelho, de Erico Veríssimo. A partir de las acciones de los personajes y el desarrollo del relato, se desarrollaron secuencias didácticas que apuntan al desarrollo de la construcción de relaciones topológicas. Este artículo, parte de una investigación cualitativa y bibliográfica, presenta tres secuencias didácticas creadas. La investigación, en su conjunto, utiliza referencias que discuten las teorías de Piaget, el potencial de la literatura para la enzeñanza de diferentes disciplinas y la impregnación mutua que se produce entre la lengua materna y la lengua matemática, que se presentan brevemente en este texto. Como resultado, se percibe que es posible, considerando estas referencias, crear secuencias didácticas que instiguen el desarrollo de dimensiones topológicas en los primeiros años, así como pensar en una forma diferente de componer la enseñanza y el aprendizaje de las matemáticas, con el objetivo de mejorar la capacidade interpretativa de estudiante y dando espacio a aspectos subjetivos como la afectividad y la creatividad.

Palabras-clave: Literatura infantil. Relaciones topológicas. Cuentacuentos. Lenguaje matemático y lengua materna.

\section{INTRODUÇÃO: UM ENCONTRO ENTRE JEAN PIAGET E ERICO VERÍSSIMO}

Este artigo é oriundo de uma dissertação que colocou em diálogo a literatura infantil com a teoria de Piaget, cujo escopo era discutir a possibilidade de, a partir da contação de histórias nos anos iniciais, elaborar momentos de aprendizagem das noções topológicas elementares.

É importante destacar que esta dissertação ${ }^{3}$ preocupou-se em investigar a possibilidade e a potencialidade de se criar sequências didáticas que visavam ao ensino das relações topológicas elementares nos anos iniciais, a partir de uma obra literária infantil - um movimento novo e necessário, já que um estado do conhecimento previamente construído (WEISSHEIMER; MONTOITO 2020a) revelou que, embora houvesse pesquisas feitas sobre literatura infantil e geometria, nenhuma dentre as encontradas contemplava o objeto "noções topológicas elementares". Deste modo, a dissertação construída não se preocupou em aplicar e validar as atividades com alunos, mas sim em abrir caminhos para discussões teóricas que possam servir de estímulo e material de pesquisa para outros professores e pesquisadores interessados em fazer movimentos de aproximação da literatura infantil com tópicos matemáticos dos anos iniciais.

Para atingir tal intento, a pesquisa foi dividida em duas grandes partes: na primeira, fez-se necessário um estudo aprofundado da maneira como a criança constrói a noção de espaço (segundo Piaget) e das potencialidades pedagógicas da literatura; na segunda, escolheu-se um livro infantil a partir do qual se elaborou sequências didáticas diversas. Neste texto serão apresentados parte do embasamento teórico da respectiva dissertação e três sequências construídas, as quais podem ser reapropriadas pelos professores e cumprem, também, o papel de convidá-los a pensar

3 De título Literatura infantil e o ensino de Geometria nos anos iniciais: As aventuras (topológicas) do avião vermelho, a dissertação foi defendida no Mestrado Profissional em Educação e Tecnologia do IFSUL, em 2020. 
nas inter-relações possíveis entre literatura e matemática de modo a, futuramente, poderem criar as próprias sequências a partir dos livros com os quais optarem trabalhar.

Assim, inicialmente destaca-se o suíço Jean Piaget (1896-1980), epistemólogo e psicólogo, que trouxe significativas contribuições para a educação. Segundo Dolle (1987, p.19), o pesquisador consagrou sua vida "à explicação biológica do conhecimento". Na perspectiva que traçou, abordou o estudo do desenvolvimento do pensamento pontuado por algumas preocupações do tipo: Qual é a gênese das estruturas lógicas do pensamento da criança, como funcionam e quais são os processos do conhecimento que a criança põe em ação?

Considerando seus estudos acerca da evolução do pensamento da criança, as suas primeiras grandes pesquisas remetem-se à problemática concernente ao pensamento lógico da criança, passando a padronizar os testes de raciocínio de Burt (1919), que são essencialmente verbais, e fazendo uso do método de observação. Porém, Dolle (1987) observa que, embora os testes de Burt tivessem méritos certos quanto ao diagnóstico, era muito mais interessante para Piaget tentar descobrir as razões por que algumas crianças fracassavam nele. Por essa razão, emprega o novo método, o método clínico, com o fim de descobrir algo sobre os processos de raciocínio que se encontravam por trás das respostas corretas, com um interesse particular por aqueles que escondiam as respostas erradas. Esse novo método leva Piaget à descoberta de que "a lógica não é inata, ao contrário, ela se desenvolve pouco a pouco, fato de observação de acordo com suas ideias teóricas anteriores". (DOLLE, 1987, p. 20). 0 método caracteriza-se pela livre conversação com a criança sobre um tema dirigido pelo interrogador, que segue as respostas dadas por ela, que the pede que justifique 0 que diz, explique, diga o porquê, que lhe faz contra sugestões.

A fim de discutir e apresentar seus estudos acerca da evolução do pensamento da criança em relação à importância das experiências espaciais mais elementares que se impõem para a construção dos saberes matemático-geométricos, Piaget destaca inicialmente a construção da inteligência sensório-motora, que se constitui de um universo que está inteiramente centrado no corpo e na ação, voltado a um egocentrismo tão total quanto inconsciente de si mesmo, mas que é ligado, ao mesmo tempo, aos progressos da percepção e da motricidade. Ao descrever o espaço sensório-motor, Piaget e Inhelder (2006, p. 11) comentam:

0 desenvolvimento mental neste estádio é rápido e importante, pois a criança elabora o conjunto de subestruturas cognitivas, que servirão de ponto de partida para as suas construções perceptivas e intelectuais ulteriores, assim como certo número de reações afetivas elementares, que lhe determinarão, em parte, a afetividade subsequente.

A esse respeito Piaget esclarece que, "para que um novo instrumento lógico se construa, é preciso sempre instrumentos lógicos preliminares; quer dizer que a construção de uma nova noção suportará sempre substratos e subestruturas anteriores" (PIAGET, 1973, p. 14). Assim, as estruturas sensório-motoras constituem a origem das operações ulteriores do pensamento, cujo desenvolvimento adquire grande extensão até a aparição simultânea da linguagem e da representação figurada que coincide com o pensamento intuitivo, estabelecendo relações de objetividade com o mundo exterior e permitindo consciência de si e do mundo.

A linguagem supõe um sistema de operações interiorizadas, sendo necessário primeiramente executá-las materialmente em ações para, em seguida, ser capaz de construí-las em pensamento. Daí a necessidade de se colocar, nas mãos da criança, materiais manipuláveis que permitam a realização 
de operações concretas. Vale ressaltar que essas operações recaem diretamente sobre os objetos, agindo sobre e conferindo a essas ações uma estrutura operatória compatível e reversível que garante a conservação dos pontos de partida na construção espontânea de estruturas lógico-matemáticas.

No contexto da educação matemática, Piaget (1973) observa que o papel inicial das ações interiorizadas e das experiências lógico-matemáticas concretas é precisamente 0 da preparação necessária para chegar-se ao desenvolvimento do pensamento dedutivo, o qual corresponde à abstração lógica e matemática.

É, a partir do encontro entre Piaget e Veríssimo, pensadores de áreas distintas, que se atenta à ideia de se perceber a literatura infantil como elemento potencializador para a mobilização do saber matemático que visa ao desenvolvimento da construção das relações topológicas mais elementares nos anos iniciais. Assim, a literatura adentra a teoria piagetiana. Enfatizando a importância de entrelaçamentos pedagógicos, Colomer (2007, p. 161) comenta:

Inter-relacionar os campos de aprendizagem e deixar resvalar a literatura entre as fendas é um modo de operar muito vantajoso para as crianças, tanto porque amplia seu contato com a literatura e seu convencimento de que ela faz parte do mundo, como pelo seu poder de converter as demais aprendizagens em algo mais vivo.

Para a dissertação, foi escolhida uma obra infantil de Erico Veríssimo (1905-1975), um escritor gaúcho, defensor das concepções socialistas e democráticas, o qual se tornou uma voz incansável contra a ditadura e o totalitarismo. Em sua constante atuação como intelectual público, Minchillo (2018, p. 12) comenta que "o próprio autor gaúcho se considerava 'dentro do campo do humanismo socialista', um defensor das liberdades, dos direitos e da justiça social”. Dentre sua vasta obra, produziu seis livros destinados às crianças no período de 1936 a 1939. Estas histórias infantis dão vazão à preocupação do autor com valores éticos e humanos, que na narrativa são construídos a partir das experiências de seus personagens, além de oportunizarem conhecimento de mundo à medida que as cenas se desenrolam em diferentes lugares e espaços.

Neste contexto, à história de Veríssimo As aventuras do avião vermelho, publicada pela primeira vez em 1936 e com sucessivas edições até os dias atuais, a partir da contação de histórias, convida a criança a adentrar e compartilhar o imaginário da narrativa, tornando a história uma importante aliada para o desenvolvimento de noções matemático-geométricas, por meio de uma interlocução da língua materna com a linguagem matemática (a primeira emerge da leitura da história, feita pelo professor; a segunda diz respeito à manipulação pedagógica da história pelo professor, conforme as sequências que serão comentadas adiante).

A narrativa começa no mundo real e depois vai para o da fantasia. No começo, tem-se um núcleo familiar composto pela mãe, pelo pai e 0 único filho, Fernando, um menino travesso, brigão $\mathrm{e}$ valente. 0 pai, na tentativa de acalmá-lo, o presenteia com um livro. Quando o menino recebe o livro contando histórias de um aviador valente, Fernando se transporta para um mundo fantástico de aventuras, levando junto seus brinquedos: 0 boneco Chocolate e 0 ursinho Ruivo, para viajarem com 0 Capitão Tormenta, codinome que ele assume ao se tornar o piloto do aviãozinho vermelho. Enlaça-se à trajetória de Fernandinho e seus companheiros outros personagens, como os cavalos que viviam na Lua e tinham cabeça de vaca e corpo de elefante e os homens que tinham pernas de sapo e olhos de mosca. Apesar de já ter tido várias edições, a utilizada na pesquisa é a de publicação mais recente, cuja imagem se vê a seguir. 
Figura 1 - Capa de "As aventuras do avião vermelho"

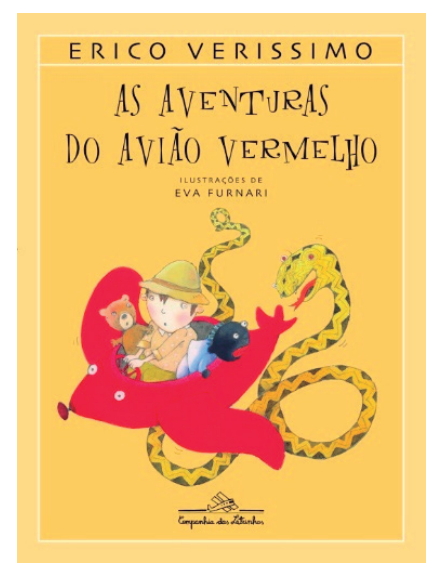

Fonte: Veríssimo, 2017

Logo, partindo da ideia de que a linguagem matemática ancorada à língua materna pode buscar refúgio na literatura infantil por meio da contação de histórias e favorecer momentos de aprendizagens no que diz respeito ao desenvolvimento das relações topológicas, elaborou-se, a partir dos trechos As aventuras do avião vermelho, sequencias didáticas que permitem ao professor uma nova maneira de compor o ensino e aprendizagem dos conceitos matemático-geométricos, o que contribui para tornar a atividade em sala de aula mais lúdica e significativa.

\section{RELAÇÕES TOPOLÓGICAS: UMA ABORDAGEM VIA LITERATURA}

A geometria constitui parte importante do currículo da escola porque é nela que a criança encontra 0 ambiente mais propício ao desenvolvimento das habilidades de observação, visualização espacial, argumentação, representação gráfica, habilidades lógicas e a comunicação de relações espaciais entre os objetos e elementos do dia a dia. De acordo com Nacarato e Passos (2003), a geometria deve ser considerada um instrumento para a compreensão, descrição e interação com o espaço em que se vive, por ser 0 campo mais intuitivo e concreto da matemática e o mais ligado à realidade.

A intuição geométrica é essencialmente ativa, ou seja, as experiências que o espaço produz são experiências feitas pelo sujeito sobre suas próprias ações e consistem em determinar como essas ações ligam-se umas nas outras (PIAGET e INHELDER, 1993). A interiorização das ações espaciais é efetuada em etapas muito graduais às quais não se pode atribuir uma data cronológica, pois a aquisição das estruturas do pensamento é intrínseca a cada sujeito e podem variar dependendo do contexto social, cultural e afetivo no qual a criança encontra-se inserida. Tal processo, na visão de Piaget, constitui também o caráter integrativo, ou seja, as estruturas construídas num período se tornam parte integrante das estruturas da etapa seguinte. Logo, nas palavras de Piaget e Inhelder (1993, p. 470), geneticamente, "as relações topológicas precedem as estruturas projetivas e euclidianas e estas encontram-se, em situação de equivalência do ponto de vista da complexidade[...]". Nesse sentido, a topologia "constitui o capítulo mais elementar da Geometria" (DOLLE, 1987, p. 151), uma vez que ignora as retas, as distâncias, os ângulos etc e só versa sobre os corpos elásticos e deformáveis, mas sem as rupturas nem recobrimentos. 
Cumpre-se então reafirmar que, geometricamente, Piaget, Beth e Mays (1974, p. 57) esclarecem que, quanto às estruturas de ordem:

Axiomaticamente, a topologia deve situar-se no ponto de partida da construção geométrica, apesar delas poderem ser derivadas paralelamente, por um lado, da geometria projetiva, e a métrica euclidiana, por outro; ademais, os grupos projetivos e os grupos de deslocamento euclidiano estão unidos entre si por estruturas intermediárias, tais como os grupos da geometria afim e 0 de similitudes.

Ao voltar-se para os documentos da Educação Básica, a Base Nacional Curricular (BRASIL, 2017, p. 272) propõe a geometria para os anos iniciais do ensino fundamental e destaca:

No Ensino Fundamental - Anos Iniciais, espera-se que os alunos identifiquem e estabeleçam pontos de referência para a localização e o deslocamento de objetos, construam representações de espaços conhecidos e estimem distâncias, usando, como suporte, mapas (em papel, tablets ou smartphones), croquis e outras representações. Em relação às formas, espera-se que os alunos indiquem características das formas geométricas tridimensionais e bidimensionais, associem figuras espaciais a suas planificações e vice-versa. Espera-se, também, que nomeiem e comparem polígonos, por meio de propriedades relativas aos lados, vértices e ângulos. 0 estudo das simetrias deve ser iniciado por meio da manipulação de representações de figuras geométricas planas em quadriculados ou no plano cartesiano, e com recurso de softwares de geometria dinâmica.

A BNCC - anos iniciais, ao valorizar as situações lúdicas de aprendizagem, contempla a ideia de Piaget, Beth e Mays (1974), que comentam que toda a operação mental deve ser considerada como uma forma das operações concretas. Deste modo, há um espaço entre as construções perceptiva e representativa para fornecer uma teoria adequada à intuição geométrica que é essencialmente ativa, ou seja, todas as formas de intuição repousam em ações; ação de colocar cada vez mais próximo (vizinhança), ou em uma sucessão definida de ordem, de envolver, de aproximar e afastar, de aumentar e diminuir etc.

A criança vai elaborando o espaço de acordo com as explorações que faz do mundo que a rodeia e, deste processo, é importante destacar que a geometria pode ser vista como imagens que ela percebe por meio dos movimentos, partindo do reconhecimento do corpo. Nesta direção, Nacarato e Passos (2003, p. 78) pontuam que a visualização e a representação são fundamentais para a geometria, pois

Os diferentes tipos de visualização [...] dizem respeito à capacidade de criar, manipular e ler imagens mentais, de visualizar informação espacial e quantitativa e interpretar visualmente informação que lhes seja apresentada; de rever e analisar situações anteriores com objetos manipuláveis. Já a representação, segundo os autores, poderá ser gráfica, como um desenho em um papel ou um modelo manipulável, considerando-se como um instrumento para expressar nossos conhecimentos e ideias.

Entende-se assim que, com o desenvolvimento dos gestos do tato e da visualização, a criança pode apreender perceptivamente as relações espaciais topológicas elementares, que são as de vizinhança, de separação, de ordem ou sucessão espacial, de circunscrição ou envolvimento e de continuidade. 
Portanto, a partir do estudo de Piaget (1993), a relação espacial mais elementar que a percepção pode apreender é a de vizinhança, a qual corresponde à condição mais simples de toda a estrutura perceptiva, isto é, a proximidade dos elementos percebidos num mesmo campo. Com o seu desenvolvimento, o fator proximidade diminui e os elementos de um todo podem ser relacionados a distâncias menores. No trecho, extraído da narrativa de Veríssimo, a relação de vizinhança se faz notar:

Fernandinho foi tomar seu leite. Uma mosca veio voando e sentou na beira da xícara. [...]. Não havia mais ninguém na sala. Só o nosso amigo gordo e brigão. Então a mosca começou a falar com voz muito fina. [...]. (VERíSSIMO, 2017, p. 9)

Ao voltar-se para 0 excerto observa-se que Fernandinho e a mosca ocupam a mesma xícara para manter um diálogo, ou seja, a mosca está situada à beira da xícara que é a mesma utilizada pelo menino para tomar o leite, conferindo assim a relação de vizinhança caracterizada pela proximidade dos elementos num mesmo campo.

Dando continuidade, Piaget e Inhelder (1993) explicam que a segunda relação espacial elementar é a da separação, que corresponde a uma relação espacial perceptiva muito primitiva e que intervém na segregação das unidades dentro de uma totalidade, ou seja, entre dois elementos vizinhos pode-se introduzir uma relação de separação que consiste em dissociá-los ou, pelo menos, fornecer um meio de distingui-los como separados. Tal relação pode ser percebida no excerto:

Então 0 Capitão Tormenta levou 0 avião para a Lua. [...]. Os três aventureiros começaram a olhar para os lados e viram uma tabuleta numa casa. Estava escrito: SETEVROS. [...]. Entraram. Era uma loja muito engraçada. Os três fregueses ficavam do lado de dentro do balcão. Os empregados ficavam do lado de fora (VERÍSSIMO, 2017, p. 22).

A história apresenta um elemento que está entre os fregueses e os empregados numa relação de separação: o balcão, ou seja, quanto mais analítica for a percepção, mais as relações de separação serão determinadas, apresentando uma evolução em relação à idade. No entanto, com as relações de separação aumentando e as de vizinhança diminuindo de importância, os progressos da análise levam a criança a estabelecer separações cada vez mais numerosas entre os elementos inicialmente indiferenciados.

Uma relação um pouco mais complexa que se estabelece entre elementos ao mesmo tempo vizinhos e separados é a relação espacial de ordem, ou de sucessão espacial. Piaget (1993) explica que ela percorre uma sequência de elementos dispostos de maneira constante, quando distribuídos em sequência a partir de pontos de referência ordenados ou de movimentos habituais. Diante da curiosidade de Fernandinho, explicam-se tais características:

Certo dia o pai lhe mostrou o globo e disse:

- Meu filho, o mundo é assim redondo.

- Papai - pediu Fernando -, me mostra onde fica a China.

Papai apontou 0 dedo.

- Fica aqui.

- E a Índia?

Papai mostrou um lugar encarnado. 


\section{- E o Brasil?}

0 dedo do papai parou em cima duma grande mancha amarela.

- Se aqui é o Brasil, papai, onde é que nós estamos?

Papai apontou para um pontinho preto, pequenino, onde estava escrito o nome de uma cidade (VERISSIMO, 2017, p. 12).

Ao observar o globo terrestre, Fernandinho vê que os países apresentam-se representados graficamente, obedecendo a uma ordem posicional exata; são vizinhos, porém estão separados. Assim, a relação de ordem intervém muito precocemente e é suscetível de desenvolvimentos ulteriores em função da complexidade dos conjuntos a serem percebidos.

Posteriormente, o que se constitui é a relação de circunscrição ou envolvimento, ou seja, um elemento pode ser igualmente percebido como rodeado por outros. A relação de circunscrição ou envolvimento e interioridade também pode ser percebida na narrativa:

Os três valentes estavam comendo quando de repente apareceu um porco gordo, abriu a boca e os engoliu. [...] Dentro da barriga do animal, os três companheiros agora estavam no escuro (VERISSIMO, 2017, p. 28).

0 filho do chefe brincava, muito contente, com 0 avião vermelho.

- Estamos perdidos! - disse o Capitão Tormenta.

Ficaram prisioneiros dentro dum porongo. 0 porongo era muito escuro (VERÍSSIMO, 2017, p. 30).

Nos trechos anteriores aparecem explicitamente as relações de interioridade: as personagens foram engolidas e estão "dentro da barriga do animal", de onde escapam para, depois, acabarem "prisioneiros dentro de um porongo". Tais descrições assumem grande importância em relação à representação espacial de situações ocorridas no interior das coisas.

Finalmente, apresenta-se, por trechos da narrativa, a relação de continuidade (que na teoria consideram os casos das linhas retas e das superfícies dadas):

E, bem como tinha acontecido com o lápis que ficava do tamanho dum alfinete, Fernandinho foi ficando pequenino, pequenino, até chegar à altura do dedo minguinho da mão do papai (VERÍSSIMO, 2017, p. 18).

Depois os três ficaram parados debaixo do vidro de aumento. E foram crescendo, crescendo... Fernandinho bateu com a cabeça no vidro. E continuou a crescer, crescer, até que ficou como era antes (VERÍSSIMO, 2017, p. 40).

A percepção das continuidades poderá modificar-se em função do aperfeiçoamento crescente dos liminares; a criança consegue perceber que as linhas são grandes e diferentes. 0 estudo das noções de contínuo completa a aquisição dos aspectos do espaço topológico pela criança. Logo, acerca do estudo das relações espaciais mais elementares, constata-se que, segundo Piaget e Inhelder (1993), o espaço topológico é interior a cada figura, com propriedades intrínsecas em oposição às relações espaciais do espaço projetivo e euclidiano. 
Assim, a construção da noção de espaço exige aprendizagem e deve ser sistematicamente elaborada em diferentes momentos, pois "a geometria é a matemática do espaço, espaço esse que precisa ser interpretado. [...] 0 papel do educador matemático é ajudar os alunos a adquirir conhecimentos e habilidades que thes possibilitem uma interpretação desse espaço" (NACARATO e PASSOS, 2003, p. 84).

0 que se mostrou até aqui, ainda que brevemente, é que a literatura infantil pode, via momentos de contação de histórias, ser mais uma aliada para o professor, pois as inter-relações entre a linguagem matemática e a língua materna intermedeiam - e colaboram com - o processo de aprendizagem (MACHAD0, 2011). No entanto, faz-se necessário manipular pedagogicamente a história, isto é, ir além da sua leitura e utilizá-la como fomentadora de momentos de aprendizagem por meio de outras atividades ou sequências didáticas extra narrativa, a fim de possibilitar uma melhor aprendizagem das noções elementares da geometria.

Nesta direção, na próxima seção discute-se com maior profundidade teórica as potencialidades da literatura infantil para 0 ensino de geometria e retoma-se o livro infantil As aventuras do avião vermelho, com o propósito de ressignificar a obra literária a partir da elaboração de sequências didáticas que podem ser exploradas para a construção do desenvolvimento das noções topológicas mais elementares.

\section{POTENCIALIDADE DA LITERATURA INFANTIL PARA 0 ENSINO DA GEOMETRIA}

Considerando a diversidade das criações literárias a que se dispõe como herança cultural, destaca-se, como citado anteriormente, a história As aventuras do avião vermelho, de Veríssimo. Destinada às crianças, ela foi tomada na pesquisa como potencializadora para o diálogo entre a língua materna e a linguagem matemática. Dela é possível extrair elementos diversos para convidar a criança a adentrar em um mundo de criatividade, de imaginação e de afetividade, fatores indissociáveis para a aprendizagem escolar (CHACÓN, 2003) e que podem ser colocados em diálogo para ampliar a compreensão acerca das relações topológicas e sua importância para o ensino da geometria.

Muitas vezes as atividades matemáticas escolares esquecem o lado estético, lúdico ou experimental da matemática, a dimensão histórica desta ciência (dimensão sociocultural), seu suporte ao desenvolvimento da humanidade, sua relação com outras ciências e com o resto da cultura (CASIS, 2018, p. 38),

E o resultado deste processo é um ensino de matemática que solapa a criatividade e a imaginação do aluno, quando não the causa sentimentos de matofobia (ALBARELLO, 2014).

Ao considerar a literatura como uma possibilidade para contornar estes problemas, traz-se as pesquisas de Candido (2004), para quem a forma de expressão encontrada na literatura pode ser entendida como uma modalidade de construção de conhecimentos que satisfaz necessidades básicas do ser humano, como emoções e sentimentos, e também como um demonstrativo da forma com que a aquisição do saber se traduz em enriquecimento humano. Tais potencialidades são perceptíveis nas obras infantis de Veríssimo, as quais apresentam um universo ficcional em que há o predomínio de aventura e de ações em que os personagens vencem os espaços e experimentam inúmeras vivências.

Enlaça-se à trajetória de Fernandinho e seus companheiros outros personagens, como os cavalos que viviam na Lua e tinham cabeça de vaca e corpo de elefante e os homens que tinham pernas de sapo e olhos de mosca. Ao adentrar em mundos imaginários, Farias (2006, p. 56) comenta que as histórias 
são importantes no processo de aprendizagem da cultura, pois são capazes de fazer dialogar elementos do concreto com o imaginário, além de oportunizarem o contato dos estudantes com outros olhares sobre os mesmos fenômenos que transversalizam qualquer experiência de vida coletiva no planeta: 0 meio ambiente, a vida, os valores sociais, a ideia de futuro.

Ao voltar-se para As aventuras do avião vermelho, se reconhece na história um enredo divertido que explora aventuras pouco comuns e que possibilita à criança dar vazão ao seu imaginário, o que adiciona a tais aventuras uma potencialidade pedagógica que podem contribuir para dar um significado mais lúdico às atividades em sala de aula. Não obstante, ao debruçar-se na obra para se estabelecer discussões acerca do desenvolvimento do pensar geométrico, é preciso perceber e interpretar situações possíveis de serem ressignificadas pelo professor com a intenção de auxiliar o aluno no desenvolvimento das relações topológicas, na construção do espaço, a partir do entrelaçamento com a narrativa.

Sendo assim, a narrativa de Veríssimo encontra apoio nas palavras de Machado (2012, p. 19), que comenta que 0 desejo de reencantar a Matemática é possível por meio da manipulação da literatura infantil com suas fantásticas, criativas e extraordinárias histórias, as quais podem servir de alicerce para o ensino da geometria - e de outros conteúdos - nos anos iniciais.

Os contos de fada são naturalmente encantados. A Matemática um dia já foi, como nos lembram os textos de Malba Tahan e de Monteiro Lobato. Hoje, a concentração das atenções em seus aspectos prático-utilitários contaminou nossa visão e quebrou o seu encanto. É preciso, pois, reencantar a Matemática.

Ao buscar refúgio na literatura, o professor brinca com o inesperado, uma vez que as reações das crianças ao ouvirem uma história - e ao quererem participar da contação - são espontâneas. A compreensão de uma história envolve conteúdos particulares e ganha diversos significados ao ser lida por diferentes leitores ou, até mesmo, ao ser apreciada em distintos momentos da vida, por uma mesma pessoa. É possível ainda que, quando uma criança leia uma história, desperte nas outras 0 desejo de também adentrar neste mundo potencialmente mais encantador e fabuloso, narrado pela voz do colega, experimentando aquilo que a história protagoniza. Nesta direção, destaca-se que "à medida que a criança cresce e sua compreensão dos textos vai se ampliando, é bom lembrar que 0 diálogo que se estabelece entre ela - na posição de leitor, ainda que seja como ouvinte, com alguém lendo para ela - e 0 texto é, seguramente, uma oportunidade de aprendizado, de ampliação de referências, de confronto com o mundo" (MARIA, 2009, p. 140).

Logo, dirige-se à literatura, neste artigo, um olhar que a entende como expressão e catalisador de criatividades e afetividades que oportuniza à criança, a partir das práticas leitoras, a compreensão de mundo, de homem e das relações entre a razão e a emoção. Este ponto de vista é contemplado pelo diálogo que se pode compreender entre o Referencial Curricular Gaúcho e a BNCC, que acena para garantir a apropriação da linguagem literária em suas especificidades contextuais, temáticas, estilísticas e composicionais. Ao recomendar a realização de atividades que permitam o contato direto e contínuo dos estudantes com diversas obras, o documento gaúcho pontua, dentre as Competências específicas da Língua Portuguesa para o ensino fundamental dos anos iniciais, 0 aspecto a seguir: 
Envolver-se em práticas de leitura literária que possibilitem o desenvolvimento do senso estético para fruição, valorizando a literatura e outras manifestações artístico-culturais como formas de acesso às dimensões lúdicas, de imaginário e encantamento, reconhecendo o potencial transformador e humanizador da experiência com a literatura (RIO GRANDE DO SUL, 2018, p. 198).

Fazendo valer a composição do documento, deve-se destacar que não se pode considerar a leitura sem que se estabeleça um vínculo com a emoção e a afetividade. 0 texto literário constitui uma forma peculiar de representação e estilo em que predominam a força criativa da imaginação e a intenção estética; além disso, ele suscita, no leitor, emoções e reflexões tão particulares e potentes que a literatura, tal qual o cinema, é reconhecida por Morin (2004) como sendo uma escola de vida.

Em adição ao documento exposto, Baldi (2009), ao referir-se à contação de histórias na escola, alerta que 0 conhecimento deve chegar às crianças por meio da literatura infantil da melhor qualidade que se dispuser, comentando:

[...] que as crianças ouçam e se apropriem da linguagem escrita, antes mesmo de estarem alfabetizadas e poderem elas próprias ler; mesmo se não entenderem tudo, cada palavra, podem sim, e devem ser trabalhadas para entenderem a ideia geral e se apropriarem do sentido; 0 texto deve ser lido integralmente às crianças, explorando-se antes, durante ou depois, conforme a sua idade e as necessidades que ele impõe, os sentidos e as impressões que lhes causam (BALDI, 2009, p. 13).

Com 0 intuito de dialogar a respeito da interlocução entre a literatura infantil e 0 desenvolvimento da construção das noções topológicas pelas crianças, destaca-se, ainda, o que diz Machado (2012, p. 18):

Um bom professor, e especialmente um bom professor de Matemática, é sempre um bom contador de histórias. Os contos de fadas constituem uma importante fonte de inspiração para a organização das aulas de matemática, sobretudo pelo modo como os contextos ficcionais são explorados.

Por isso, advogar pela interlocução entre As aventuras do avião vermelho e a construção das noções topológicas pelas crianças dos anos iniciais é um modo de propiciar, ao aluno, além da aprendizagem matemática, a possibilidade de compreender nos outros o que não compreende na vida comum; " nessa vida comum, percebemos os outros apenas de forma exterior, ao passo que na tela e nas páginas do livro eles nos surgem em todas as suas dimensões, subjetivas e objetivas" (MORIN, 2004, p. 50).

Do exposto, esta pesquisa convida os professores a considerarem a possibilidade de a criação literária adentrar nos currículos como um recurso intelectual e afetivo poderoso para o ensino e a aprendizagem das diversas áreas do conhecimento, na exploração de temas elencados pelo professor para serem desenvolvidos nos anos iniciais.

Na literatura, o que age como força afetiva é a própria história, ou seja, a capacidade de a criança criar e imaginar a narrativa, estando aberta às experiências dos personagens. Em suas histórias infantis, Veríssimo (2017) criou um universo ficcional em que há o predomínio de aventuras e ações, no qual os personagens vencem espaços e crescem a partir das próprias experiências; ao mesmo 
tempo, diversas cenas servem de recurso para a exploração de situações que favoreçam a criação de sequências didáticas, pensadas para o desenvolvimento das relações de vizinhança, separação, ordem ou sucessão espacial, circunscrição e continuidade ${ }^{4}$.

\section{SEQUÊNCIAS DIDÁTICAS: ENTRELAÇAMENTO ENTRE GEOMETRIA E LITERATURA INFANTIL}

Partindo da ideia de que a contação de histórias pode ser vista pelos professores dos anos iniciais como uma aliada para 0 ensino da geometria, serão apresentadas três sequências didáticas construídas visando à ressignificação da história As aventuras do avião vermelho, do ponto de vista matemático-geométrico. Conforme dito anteriormente, as sequências didáticas criadas são apenas sugestões aos professores, podendo ser incluídas na ação pedagógica no formato em que se apresentam ou modificadas a partir do contexto em que se desenrolam.

Sobre as sequências didáticas, é mister entender que sua elaboração não é automática e que devem ser considerados alguns aspectos: escolha de tema gerador, delimitação do conteúdo/conceito/ ideia a ser ensinado, seleção de materiais para sua elaboração; além disso, é preciso que se tenha uma previsão de resposta e, também, um entendimento dos possíveis erros que 0 aluno poderá vir a fazer pois, sem se pensar nos erros, fica difícil ajustar a sequência para que ela seja clara, objetiva e instrutiva (WEISSHEIMER, 2020). Ainda, Peretti e Costa (2013) definem a sequência didática como sendo um conjunto de atividades ordenadas, estruturadas e articuladas para a realização de certos objetivos educacionais.

É importante destacar que as sequências didáticas foram planejadas para as crianças dos anos iniciais, as quais se encontram no período pré-operatório, o que correspondente ao período de desenvolvimento das noções topológicas. As sequências aqui apresentadas foram pensadas para estimular o desenvolvimento das relações topológicas de circunscrição e ordem, visando auxiliar 0 aluno na construção e interpretação do espaço, a partir da contação de histórias. Isto não quer dizer que o professor deva aplicá-las somente após a leitura da narrativa, uma vez que ele pode optar, de acordo com seu planejamento, por intercalar a leitura com as sequências didáticas.

Na perspectiva da impregnação mútua entre a língua materna e a linguagem matemática (MACHADO, 2011) criou-se, para cada sequência, um título que remete à ideia principal do excerto, o que pode favorecer uma aproximação cognitiva e afetiva da criança com a obra de Veríssimo. Além disso, o desenvolvimento de cada sequência didática levou em consideração os seguintes passos:

1) Retirou-se para cada sequência um pequeno trecho das aventuras vivenciadas pelos personagens que, sugere-se, seja lido às crianças, como recurso pedagógico e afetivo, visando estimular e estabelecer diálogo entre a história e as relações topológicas.

2) Estabeleceu-se qual das noções topológicas mais elementares para a representação do espaço se queria trabalhar com cada sequência.

3) Previram-se alguns resultados esperados, bem como possíveis equívocos, para que se pudesse analisar se as sequências estavam bem construídas e claras. Isto é importante para se compreender se o professor conseguiria fazer uso delas e se 0 aluno entenderia 0 que ela solicitava.

A elaboração das sequências traz, em si, um pequeno texto criado para o professor, o roteiro de desenvolvimento das atividades, a lista de materiais utilizados e uma sugestão de lugar para 0

4 Embora neste artigo sejam comentadas apenas três exemplos, por ser a pesquisa oriunda de um mestra-do profissional, gerou, como produto técnico, é um livreto com sequências didáticas que, pensadas a partir da narrativa de Veríssimo, visam desenvolver as relações citadas. Este livreto (WEISSHEIMER; MONTOITO, 2020) pode ser consultado no link: https://educapes.capes.gov.br/handle/capes/573008 
desenvolvimento das atividades. É preciso dizer que as sequências aqui sugeridas não são as únicas que poderiam ser criadas a partir dos excertos selecionados; ainda, são sugestões de abordagens pedagógicas que podem ser modificadas ou adaptadas pelos professores.

\section{$1^{\text {a }}$ Sequência didática: Organizando a mala do Capitão Tormenta}

Uma viagem imaginária e fantástica! Fernandinho e seus companheiros passeiam pela Lua, pela China, pela África e chegam à Índia. Esse percurso cheio de ventanias e relâmpagos poderá instigar as crianças a interessarem-se por diferentes modos de perceber o mundo, tanto numa dimensão real como ficcional, possibilitando a elas experiências afetivas e cognitivas.

A organização da mala do Capitão Tormenta é uma atividade lúdica que favorece a ação das crianças para o pensar geométrico desde a solicitação dos materiais feita pelo professor. Deste modo, o professor deverá organizar a turma antecipadamente, solicitando que as crianças tragam para a escola malas de viagem vazias, roupas de verão, roupas de inverno, potes de geleia, potes de biscoito e pencas de banana. A turma poderá ser dividida em grupos conforme a quantidade de malas que se dispuser, seguindo a orientação do professor conforme o número de alunos da classe. Caso não seja possível se trabalhar com malas de verdade, essas poderão ser substituídas por caixas de papelão; o mesmo vale para os objetos que, se não poderem ser trazidos, podem ser substituídos por sucata (mas neste caso sugere-se que sejam colocados rótulos, para que não se esqueça o que cada coisa representa). A partir disso, as crianças de cada grupo poderão organizar-se de maneira que cada uma seja responsável por trazer determinados elementos necessários para a composição da mala. Com o material organizado e os grupos divididos, o professor dará início à atividade, destacando um pequeno trecho da história que será lida por ele.

Fernandinho esfregou as mãos [...]. E começou a se preparar para a grande viagem. Botou na sua mala roupa grossa e roupa fina. Ele sabia que na África faz calor e na Rússia faz frio.

- Que é que falta agora? - perguntou [...]. Falta comida. Um explorador valente também precisa comer.

Foi até o guarda-comida e trouxe de lá um pote de geleia, uma lata de biscoitos e um cacho de bananas.

- Agora não falta mais nada.

A partir da leitura do trecho, o professor poderá solicitar às crianças que compartilhem suas vivências de viagens (curtas ou longas) com seus colegas, usando esta experiência como motivadora e contextualizadora da atividade proposta.

Em seguida, as crianças serão orientadas para a realização das tarefas, utilizando o material trazido por elas.

Objetivo: desenvolver as noções espaciais de circunscrição e ordem associadas às relações de espessura.

Local: sala de aula 


\section{Material:}

Malas de viagem vazias ou sacolas de viagem,

Roupas de inverno,

Roupas de verão,

Potes de geleia,

Lata de biscoitos,

Penca de bananas.

\section{Atividade:}

$1^{0}$ momento

Como Fernandinho tem uma mala bem pequena, é preciso organizá-la de forma que caiba tudo dentro dela. Por isso será necessário seguir as seguintes orientações:

Em primeiro lugar, no fundo da mala, coloquem as roupas de inverno, as mais grossas.

Em seguida, guardem as roupas de verão, as mais finas.

E, por fim, ponham os potes de geleia, a lata de biscoitos e a penca de bananas.

\section{$2^{0}$ momento}

Cada grupo poderá mostrar e comentar a organização dos apetrechos colocados em sua mala, que será semelhante à arrumação da mala de Fernandinho.

Resultados esperados: que a criança desenvolva noções do conceito de ordem e circunscrição a partir da atividade de organização de objetos dentro de um espaço limitado, e de interioridade, estabelecendo relações com suas vivências ou desejos de viagem. É uma proposta simples, porém a criança poderá equivocar-se com a ordem dos objetos, o que causaria, nesta situação, uma lambuzeira total na mala, já que a geleia e a penca de bananas ficariam sob as roupas. Neste caso, 0 professor poderá ler novamente, solicitando a atenção da criança para compreensão da ordem de disposição dos elementos na mala.

\section{$2^{\text {a }}$ Sequência didática: Prisioneiros de um porongo}

Ouvir e imaginar os desafios experimentados pelos personagens da narrativa As aventuras do avião vermelho é munir-se de coragem para transportar-se, através da imaginação, para lugares desafiadores. E é a partir desses espaços de aventuras que se buscou extrair elementos novos que favoreçam o desenvolvimento das relações de circunscrição, destacada no trecho a seguir.

Desceram na África, mas foram muito sem sorte. Caíram bem no meio de uma aldeia.

- Estamos perdidos! - disse o Capitão Tormenta.

Ficaram prisioneiros dentro dum porongo. 0 porongo era muito escuro. 0 capitão acendeu a lanterna. Num canto da prisão via-se uma enorme formiga que caminhava na direção deles.

A partir da leitura do trecho da narrativa, o professor poderá conversar com as crianças a respeito de, repentinamente, encontrarem-se em lugares diferentes com pessoas desconhecidas, analisando como eles lidam com estes sentimentos. Em seguida as crianças, organizadas em trios, 
poderão iniciar as atividades conforme a proposta da sequência didática. Caso não se forme um último trio, a criança ou as crianças poderão juntar-se aos trios já formados. A atividade será organizada em dois momentos.

Objetivo: desenvolver as noções espaciais de circunscrição associado às relações de grandeza (maior ou menor).

Local: sala de aula

Material:

Garrafa PET para confecção do porongo (material solicitado às crianças em data anterior à elaboração da atividade em sala de aula),

Material de sucata (como tampinhas, rolinho de papel, palito de dente, palito de picolé, botões, restos de rolos de lã ou algodão etc),

Tinta ou papel escuro para caracterizar o porongo.

Argila.

\section{Atividade:}

$1^{0}$ momento

A turma, em sala de aula, será organizada em trios. Cada grupo receberá do professor uma garrafa PET cortada de forma que represente um porongo. Este poderá ser pintado pelas crianças com tinta ou forrado com cor escura, de forma que represente 0 ambiente escuro conforme o relato da narrativa. Em seguida, as crianças serão convidadas a criar, com material de sucata e argila, os personagens, observando o tamanho de cada um (Fernandinho, ursinho Ruivo e o boneco Chocolate), de forma que caibam dentro do porongo.

\section{$2^{0}$ momento}

Com os personagens em mãos, cada trio poderá imaginar e criar um novo enredo para a narrativa, explorando e brincando com seus aventureiros. No desenrolar desta atividade, será necessária a intervenção do professor para que as noções de interioridade e grandeza possam ser elaboradas pelas crianças e discutidas em seu trio. Posteriormente, os grupos poderão apresentar aos colegas suas criações artísticas (personagens e o porongo) e compartilhar com a classe, oralmente, o novo enredo para a história.

Observação: Por se tratar de uma atividade que possivelmente será elaborada em mais de um dia, o registro do desenvolvimento das etapas sucedidas para atingir o objetivo da proposta torna-se importante, uma vez que será a partir da construção e manipulação dos objetos criados pela própria criança que se dará as ações que ajudarão a desenvolver o conceito de circunscrição e grandeza. Cabe destacar que desenhos podem ser utilizados pela criança como registros, mas propõe-se que cada trio coloque seus personagens manipuláveis dentro do porongo, pois assim as crianças conseguirão compreender com maior clareza as relações entre tamanho dos objetos e interioridade.

Resultados esperados: espera-se que, a partir das orientações dadas pelo professor, 0 aluno elabore a noção de circunscrição, na dimensão de interioridade entrelaçada com a ressignificação 
do extrato. Além disso, outro resultado esperado diz respeito à relação de grandezas, já que os personagens elaborados não podem, segundo a história, ter todos o mesmo tamanho ou não caberem, juntos, dentro do porongo.

\section{$3^{a}$ Sequência didática: Por dentro e por fora das nuvens}

A natureza é uma fonte de recursos possível de ser usada para o ensino da geometria. Nela encontra-se uma infinidade de formas que possibilitam identificar e explorar conceitos e propriedades da geometria. Nesse sentido, destaca-se um pequeno trecho da narrativa As aventuras do avião vermelho, que será lido às crianças:

0 avião vermelho passou por dentro de uma grande nuvem. Existia nessa nuvem uma cidade de tico-ticos. 0 prefeito da cidade estava no barbeiro fazendo a barba e, quando viu o barulho do avião, assustou-se e saiu para fora com a cara ensaboada. Foi um susto! Todos os tico-ticos da cidade apareceram nas janelas de suas casas. Os tico-ticos mulheres e crianças começaram a chorar de medo. Os tico-ticos homens saíram para fora de espingarda em punho e começaram a dar tiros para 0 ar.

Em seguida, as crianças serão divididas em trios para a realização da atividade recreativa, a qual explora os conceitos de dentro e fora. A atividade tem apenas um momento, mas pode se repetir quantas vezes o professor desejar.

Objetivo: Desenvolver o conceito da relação topológica de circunscrição, a partir da noção de interioridade.

\section{Local:}

Pátio ou ginásio esportivo da escola / sala de aula.

Material:

Apito.

\section{Atividade:}

A turma, no pátio da escola, será dividida em trios. Apenas uma criança não comporá nenhum trio, pois ela fará o papel do avião vermelho. Cada trio deverá escolher dois colegas e estes, de frente um para o outro, com as mãos dadas, formarão uma nuvem. A terceira criança do trio se posiciona no interior da nuvem para representar o tico-tico. Se, após a divisão dos trios, alguma criança sobrar nesta formatação, esta será convidada a integrar um dos grupos, que formará uma nuvem maior. Para 0 desenvolvimento da atividade, os trios formarão um círculo de nuvens e, o colega que representa 0 avião, posicionado ao centro do círculo, irá apitar, representando o barulho do avião. Ao ouvirem 0 apito, os tico-ticos deverão sair de sua nuvem e entrar em outra. Cada nuvem poderá receber apenas um tico-tico.

0 avião vermelho, ao dar 0 sinal do apito, sairá do centro e disputará com os tico-ticos uma nuvem. Assim sempre sobrará uma criança que assumirá o papel do avião. A brincadeira terá o tempo de duração que o professor determinar.

Após as atividades, alguns registros feitos em aula podem dar ao professor informações interessantes: 0 desenho das nuvens, feito pelo professor no quadro ou pelas crianças em seus cadernos, 
pode mostrar se alguns alunos perceberam que as nuvens estavam dispostas em círculo, se havia uma maior do que as outras (isto é, formada por mais de dois colegas), se 0 avião ficava bem no centro delas etc.

Resultados esperados: ao realizar a atividade lúdica com as crianças, espera-se que o conceito das relações topológicas de circunscrição seja desenvolvido por elas de forma gradual, por meio de uma construção progressiva e contínua.

\section{CONSIDERAÇÕES FINAIS}

Considerando a importância dos estudos de Jean Piaget acerca da representação do espaço pela criança e da literatura infantil como potencalizadora para o ensino da matemática nos anos iniciais, volta-se ao objetivo deste artigo, que era discutir o desenvolvimento das relações topológicas, segundo Piaget e colaboradores, na construção do espaço pela criança, a partir de uma interlocução com a literatura infantil.

As sequências apresentadas acenam a possibilidade de se relacionar a literatura infantil com geometria - neste caso particular, planejadas para ajudar os alunos a desenvolverem as noções topológicas básicas. Em se tratando de a literatura ser material potencial para a elaboração de sequências didáticas, dois pontos importantes precisam ser considerados: a criatividade do professor e o conhecimento da teoria que embasa aquilo que deseja ensinar ou desenvolver com determinada atividade.

Dada a importância deste entrelaçamento entre a língua materna e a linguagem matemática, cabe ao professor a procura por uma literatura que possibilite trabalhar ambas conjuntamente. As pesquisas de Arnold (2016), Flores (2018) e Montoito (2019), dentre outras, mostram a possibilidade de se aliar a literatura à matemática em qualquer nível de ensino, motivo pelo qual se poderá dar continuidade às abordagens pedagógicas que consideram conjuntamente a matemática e a literatura que, sendo trabalhadas desde os anos iniciais, não causarão estranhamento aos alunos maiores.

Manipular livros de histórias é atividade essencialmente lúdica e pode ser plena de novidades. 0 fascínio de belos livros na infância pode seduzir uma criança, para sempre, para o mundo do conhecimento. $\mathrm{E}$, à medida que a criança cresce, novos desafios vêm com novos livros, num movimento também crescente (MARIA, 2009, p. 138).

A essa referência da autora, acrescenta-se e concorda-se com Piaget e Inhelder (1993), que explicam que a criança é um sujeito conhecedor, que cria e transforma a fim de aprender e compreender. Ela faz um esforço ativo e complexo para construir seus próprios entendimentos e suas interpretações, o que muitas vezes resulta em invenções, atitudes que Piaget descreve como sendo centrais na construção do conhecimento. Este é um comportamento constante no desenvolvimento do raciocínio ainda que crianças, adolescentes e adultos ajam de maneira diferente e, portanto, se afeiçoam a histórias diferentes.

É, pois, diante da discussão aqui exposta, que se destaca que o entrelaçamento entre literatura infantil e geometria pode abrir espaços, no processo de ensino e de aprendizagem, a um campo de exploração a ser descoberto e ampliado pelos professores que procuram fundamentar o desenvolvimento da estruturação do pensamento geométrico com uma compreensão mais aprofundada, consolidada, diversificada, interligada e lúdica. Deste modo, a contação de histórias, acredita-se, pode tornar-se um 
instrumento proeminente na intenção pedagógica do professor que, ao planejar sua aula, poderá fazer uso das criações literárias para a exploração, ainda, de conteúdos de diferentes áreas. A esse respeito, Colomer diz: "Quanto mais ativo e inter-relacionado é o ensino que se oferece, mais fácil será que os alunos se encontrem com a literatura em qualquer espaço ou matéria" (COLOMER, 2007, p. 160).

Logo, trazendo Erico Veríssimo para essa discussão, acredita-se que, ao ouvir a história As aventuras do avião vermelho, a criança terá a oportunidade de imaginar as aventuras narradas, de falar acerca dos locais, personagens e elementos sobre os quais estará observando e agindo, bem como representá-los por meio de recursos didáticos diversos, ampliando a sua relação com 0 espaço, a partir de práticas pedagógicas que favoreçam ações concretas, reais e manipuláveis, sobre as quais ela poderá atribuir novos conceitos e construir novas relações. Por isso, partindo da ideia de que a contação de histórias pode ser vista pelos professores dos anos iniciais como uma aliada para 0 ensino da geometria, cumprindo o papel de "fazer uma ponte" entre o mundo real das crianças e aquele representado nas páginas do livro, entende-se que esta interlocução da literatura com a geometria pode se dar a partir de sequências didáticas que, ao serem elaboradas, mostram uma articulação possível entre a linguagem matemática e a língua materna.

Ao planejar as sequências didáticas utilizando a narrativa das aventuras do avião vermelho (ou outra, que o professor escolher), registra-se que pensar Piaget na construção do espaço pela criança, a partir de uma interlocução com a literatura infantil, exige considerar a teoria piagetiana da construção das estruturas da inteligência, a qual vai se dando, hierarquicamente, das mais simples às mais complexas, e refletir acerca das relações afetivas que a criança poderá estar desenvolvendo e construindo, seja com o mundo à sua volta ou com a história escutada.

\section{REFERÊNCIAS}

ALBARELLO, Q. R. S. Um olhar sobre a matemática: fobia ou encantamento? 2014. 71 f. Dissertação (Mestrado em Educação) - Universidade Regional Integrada do Alto Uruguai e das Missões, Frederico Westphalen, 2014.

ARNOLD, D. S. Matemáticas presentes em livros de leitura: possibilidades para a Educação Infantil. 2016. 182 f. Dissertação (Mestrado Profissional em Ensino de Matemática) - Instituto de Matemática, Universidade Federal do Rio Grande do Sul, Porto Alegre, 2016.

BALDI, E. Leitura nas séries iniciais: uma proposta para formação de leitores. Porto Alegre: Projeto, 2009.

BRASIL. Base Nacional Comum Curricular: Educação Infantil e Ensino Fundamental. Brasília: MEC/Secretaria de Educação Básica, 2017.

CANDIDO, A. Vários Escritos. São Paulo / Rio de Janeiro: Duas cidades / Ouro sobre azul, 2004.

CASIS, M. Dominio afectivo y educación matemática: claves para comprender la influencia de la afectividad y las actitudes en la construcción del conocimiento matemático. Santiago: Ediciones Universidad Finis Terrae, 2018.

CHACÓN, I. M. G. Matemática emocional: os afetos na aprendizagem matemática. Porto Alegre: Artmed, 2003.

COLOMER, T.C. Andar entre livros: a leitura literária na escola. São Paulo: Global Editora e distribuidora LTDA, 2007. 
DOLLE, J. M. Para compreender Jean Piaget: uma iniciação à Psicologia Genética Piagetiana. Rio de Janeiro: Editora Guanabara S.A, 1987.

FARIAS, C. A. Alfabetos da alma: histórias da tradição na escola. Porto Alegre: Sulina, 2006.

FLORES, R. de C. V. "Viajando" com Jules Verne (1828-1905): aulas investigativas em matemática com ênfase no livro Vinte Mil Léguas Submarinas. 2018. Dissertação (Mestrado Profissional em Matemática em Rede Nacional) Universidade Estadual do Sudoeste da Bahia, Vitória da Conquista.

MACHADO, N. J. Matemática e Educação. Alegorias, tecnologias, jogo, poesia. São Paulo: Editora Cortez, 2012.

MACHADO, Nilson José. Matemática e língua materna: análise de uma impregnação mútua. São Paulo: Cortez, 2011.

MARIA. L de. 0 clube do livro: ser leitor - que diferença faz? São Paulo: Globo, 2009.

MINCHILLO, C. C. Erico Verissimo, escritor del mundo: circulación literaria, cosmopolitismo y relaciones interamericanas. Havana: Fondo Editorial Casa de Las Américas, 2018.

MONTOITO, R. Entrelugares: pequeno inventário inventado sobre matemática e literatura. BOLEMA, v. 33, n. 64, p. 892-915, 2019.

MORIN, E. A cabeça bem-feita: repensar a reforma, reformar o pensamento. Rio de Janeiro: Bertrand Brasil, 2004.

NACARATO, A. M.; PASSOS, C. L. B. A geometria nas séries iniciais: uma análise sob a perspectiva da prática pedagógica e da formação de professores. São Paulo: EdUFSCar, 2003.

PIAGET, J. Problemas de psicologia genética. Rio de Janeiro: Editora Forense, 1973.

PIAGET, J.; INHELDER, B. A Psicologia da criança. Rio de Janeiro: Difel, 2006.

A representação do espaço na criança. Porto Alegre: Artes Médicas, 1993.

PIAGET, J.; BETH, W. E.; MAYS, W. Epistemologia Genética e pesquisa psicológica. Rio de Janeiro. Freitas Bastos, 1974.

PERETTI, L; COSTA, G. M. T. Sequência didática na Matemática. REI - Revista de Educação do IDEAU. v. 8, n. 17, p. 1-14, 2013.

RIO GRANDE DO SUL. Secretaria de Estado. Departamento Pedagógico 585r. União Nacional dos dirigentes Municipais de Educação. Referencial Curricular Gaúcho: Ciências da Natureza. Porto Alegre. Secretaria de Estado da Educação, Departamento Pedagógico, 2018. v 1 - 1. Políticas Públicas- Aprendizagem-Currículo- Competências- HabilidadesFormação Continuada- Linguagens I. Título / CDU 37.01

VERÍSSIMO, E. As aventuras do avião vermelho. São Paulo: Companhia das Letrinhas, 2017.

WEISSHEIMER, R. F. Literatura infantil e 0 ensino de geometria nos anos iniciais: as aventuras (topológicas) do avião vermelho. 2020. Dissertação (Mestrado Profissional em Educação e Tecnologia) - Instituto Federal de Educação, Ciência e Tecnologia Sul-rio-grandense. Pelotas. 
WEISSHEIMER, R. F; MONTOITO, R. As aventuras do avião vermelho: Caderno de atividades (ensino fundamental anos iniciais), 2020. Disponível em: https://bit.ly/3m2veVH. Acesso em: 31 ago. 2020.

WEISSHEIMER, R. F; MONTOITO, R. Literatura infantil e geometria: conexões possíveis mapeadas pelo estado do conhecimento. Research, Society and Development. v. 9, n. 9, p. 1-23, 2020a.

RECEBIDO EM: 19 mai. 2020

CONCLUÍDO EM: 31 ago. 2020 